\title{
"OS TRAIGO LOS RECUERDOS DE ALTAZOR". CREACIONISMO Y METAPOESIA EN VER Y PALPAR, DE VICENTE HUIDOBRO
}

\author{
POR \\ BELEN CASTRO MORALES \\ Universidad de La Laguna
}

\section{VER Y PALPAR EN EL PERIODO DE 1925-1941}

Ver y palpar es el primer libro de poemas que el vanguardista chileno Vicente Huidobro publicó después de Altazor (1931). Apareció en 1941 en Santiago de Chile, el mismo año que El ciudadano del olvido. Estos dos libros suelen considerarse, junto con algunos de sus Ultimos poemas (1948) sus obras poéticas de madurez, y su fecha de publicación, diez años después de Altazor, se interpreta como interrupción de un silencio demasiado dilatado en un poeta antes prolífico. No es difícil pensar que un proyecto tan radical y drásticamente destructivo de la lengua poética como fue Altazor, obra que consuma la desaparición del poeta y de sus palabras en el vértigo de la inmolación, sólo puede dar paso al silencio. El mismo Huidobro dejó testimonio de la "importancia histórica" de este poema: "... en él están marcados todos los caminos que yo he seguido después y tal vez nunca podré salir de alguna de sus rutas" ${ }^{n}$. En este sentido George Yúdice, uno de los pocos estudiosos que se han ocupado de esta obra de 1941, no sólo aprecia cierta continuidad entre los poemas de técnica iterativa de Ver y palpar y Altazor, sino que añade: "gran parte de los poemas de este volumen son poco más que recalcos del proceso desgramaticalizador evidenciado en Altazor" (216). Efectivamente, esta obra, por otra parte heterogénea, actualiza con cierta frecuencia temas, motivos y procedimientos de Altazor. Sin embargo, y ésta es la lectura que proponemos aquí, Ver y palpar no es en absoluto una obra subsidiaria y carente de nueva significación dentro de la trayectoria de Huidobro. Por el contrario, nos muestra un momento especialmente tenso, conflictivo y germinal dentro de la poética huidobriana, cuando la creación parece ofrecerse ante el poeta como un haz de caminos divergentes.

\footnotetext{
${ }^{1}$ De una carta de Huidobro a Aurelio Miro Quesada, fechada en junio de 1931, reproducida en parte por René de Costa en su introducción a la edición de Altazor y Temblor de cielo (Madrid: Ed. Cátedra, 1981).
} 
Aunque Ver y palpar aparece en 1941, debemos atender a las fechas 19231933 situadas junto al título, pues son las que Huidobro aporta para deslindar la década en que fueron escritos estos poemas. Si las aceptamos, debemos deducir que fueron escritos en fechas muy próximas a los poemas de Automne Régulier (1918-1922) y Tout à coup (1922-1923), las dos obras en francés publicadas en París en 1925. También debemos inferir que la composición de Ver y palpar es en parte simultánea a la de Altazor -iniciado en 1919-y a la de Temblor de cielo (1928) (Madrid, 1931). También habrá que recordar que la otra obra poética de 1941, El ciudadano del olvido, está constituida por poemas escritos entre 1924 y 1934. Este simple planteamiento cronológico invalida la idea de un Huidobro que enmudeció poéticamente durante diez años después de la fuerte experiencia de Altazor, así comola generalizada tendencia a situar una frontera que marca con esta obra un antes y un después del Creacionismo. En efecto, si se tiene en cuenta la larga gestación de Altazor (entre 1919 y 1931) hemos de relativizar su importancia como hito cronológico, aunque ello no invalide su indudable carácter de hito poético. En consecuencia, más que a una delgada linealidad cronológica extendida a lo largo de las fechas de publicación de las obras mencionadas, hemos de atender a una compleja y asimétrica simultaneidad en la composición de las mismas y, por lo tanto, a una posible identidad ideológica, estilística, temática y técnica entre algunos de sus poemas.

En su libro Poesía y poética de Vicente Huidobro (1912-1931) Luis Navarrete Orta demuestra que los textos teóricos recopilados en 1925 en el libro Manifestes acusan la llegada a un punto conflictivo. Tal conflictividad coincide con los cambios sustanciales que se producen, respecto a la anterior modalidad cubista del Creacionismo, en Automne Régulier y Tout à coup, ambas publicadas el mismo año que Manifestes. Además, se observa la colisión entre fundamentos teóricos distintos y difícilmente conciliables. Como observa Navarrete Orta:

[el Creacionismo] había devenido en recipiendario de ingredientes tan dispares y aleatorios que cada vez más se parecía a un cajón de sastre, a una mezcla indeterminada de agregados; en una tendencia aluvional que se desdibujaba progresivamente y a la que era prácticamente imposible dar cumplimiento (170-171).

Por un criterio selectivo, el autor detiene su indagación sobre la teoría y la poesía de Huidobro en 1931, fecha en que se publica Altazor y en que Huidobro redacta el manifiesto "Total". La conjunción de estos dos textos, el poético y el programático, cierran, según Navarrete, el "primer ciclo" de su actividad con una novedosa apertura estética e ideológica sobre la realidad y el hombre. Evidentemente, los textos comprendidos en el "segundo ciclo" de la producción huidobriana necesitan ser estudiados con similar prolijidad que los primeros, aunque la actividad teórica de nuestro autor haya disminuido a partir de 1931 y su trabajo poético se cifre en obras poco estudiadas como sus tres poemarios Ver y palpar, El ciudadano del olvido y Ultimos poemas. 
Por otra parte, entre 1924 y 1941 la actividad de Huidobro no se centra únicamente en la poesía. Es una etapa marcada por la actividad divulgadora y polémica, por el trabajo en obras narrativas y dramáticas y por su participación en la vida política. Además, Huidobro continúa su difusión del Creacionismo, viaja constantemente, dicta conferencias y se dedica a la difusión de sus ideas revolucionarias ${ }^{2}$.

Como puede verse, este período exigiría el estudio sistemático de la prosa de Huidobro, así como la consideración de algunos textos en los que, lejos ya de definir un programa, continúa defendiendo su posición radical frente a la poesía. Incluso la obra poética de este Huidobro maduro, surrealista o existencialista, autor de una poesía más humana y social, a la vez que menos estructurada y telegráfica, necesita un nuevo enfoque: un enfoque, diríamos, menos "adjetivo" y más sustancial, capaz de imbricar sus hallazgos en un proyecto de comprensión global de toda su obra, $y$, específicamente, del período 1925-1941.

\section{UN NUEVO ESTILO PARA EL CREACIONISMO}

Nos será útil recordar la apreciación casi unánime de la crítica sobre un cambio estilístico y técnico iniciado con los dos libros publicados por Huidobro en 1925. David Bary detecta en estos poemas de Automne Régulier y Tout à coup unos "cambios técnicos" que los diferencian de su etapa cubista, aunque sostiene que ambos libros "contienen los poemas más resueltamente creacionistas de toda la producción de Huidobro" (95) y que suponen un retorno al estilo NordSud de Horizon Carré y Poemas árticos. Esos nuevos recursos técnicos se hacen patentes en el abandono del ritmo entrecortado y de la disposición espacial y

\footnotetext{
2 En 1924 había escrito la "Elegia a la muerte de Lenin". En 1925 funda en Chile el diario Acción, del que sólo llegan a salir 14 números, y la Federación de Estudiantes lo propone como candidato a Presidente de la República. En 1926 publica Vientos contrarios, un libro de aforismos y breves textos en prosa. En 1929 publica en Madrid Mto Cid Campeador, "hazaña" novelesca. En 1931 escribe el manifiesto "Total", que publicará en 1932. Ese mismo año edita en París Gilles de Ratz (1925-1926), obra de teatro que tantas afinidades guarda conAltazor y Temblor de cielo. En 1933 regresa a Chile y se une al Frente Popular Chileno al tiempo que aglutina un gru po poético de jóvenes de tendencias surrealistas que cristalizará en torno a la revista Mandrágora (1938). En 1934 publica en Santiago varios textos narrativos: Cagliostro, novela-film (1921-1922), La proxima, Papá o el diario de Alicia Mir, asi comoel guiñol En la luna. Un año después aparecerá en Santiago Tres novelas ejemplares, en colaboración con Hans Arp. Los años 1936 y 1937 están marcados por su participación en la Guerra Civil Española y en el Congreso Mundial de Escritores Antifascistas por la Libertad. Mientras tanto, sale en Chile la revista Total, de marcado sentido revolucionario. En 1939 publica otra novela: Sátirooel poder de las palabras. Ś́lo a partir de 1941, fecha en que vuelve a Europa como corresponsal de guerra, se suspende el ritmo de sus publicaciones.
} 
tipográfica de la escritura en la página. El poema vuelve a una cierta ordenación estrófica tradicional, al uso de versos más largos con cadencias regulares y a la introducción de la rima. Sin embargo, esta rima funciona como procedimiento paródico y genera contenidos arbitrarios, por lo cual su efecto en el sentido del poema es el de introducir elementos absurdos, no interpretables según su anterior lógica constructiva. Estos nuevos procedimientos nos sitúan ante una nueva concepción del poema y ante una nueva lógica poética: no estamos ya ante la imagen traducible, precepto creacionista que se cumplía en obras anteriores, sino ante unos poemas que basan su funcionamiento en el azaroso mecanismo fónico de la rima y de ciertos juegos de palabras. Entre estos juegos la repetición y la letanía proponen una concepción cíclica del tiempo antes ausente en los espacios esencializados e intemporales del estilo cubista. Como ha visto Yúdice, Huidobro continúa trabajando en estas obras la analogía y la metonimia, dos de sus recursos más característicos, pero ya no busca una estructuración rigurosa del poema ni una exploración sémica de sus componentes. Por otra parte, el sujeto poético aparece fragmentado en distintas personas gramaticales, efecto desestructurante que Yúdice relaciona con la alienación y atomización de la persona poética y con un sujeto escindido de sí mismo. De forma paralela se intensifican motivos como el viaje, la exploración, el mar, el poeta-marino y el poeta-náufrago y el ojo (símbolo de la visión poética) que configuran una "poética de la divagación" (Yúdice 129).

En el ámbito de estos cambios sustanciales inaugurados en las obras de 1925, debemos insertar Ver y palpar, pues, aparte de su vecindad cronológica en cuan to a su composición, muchos de los temas y técnicas de esta obra encuentran la clave de su significación en esos libros, en Altazor y Temblor de cielo, así como en textos prosísticos y programáticos de esos años.

El libro está formado por cincuenta poemas agrupados en dos grandes bloques: "Hasta luego" y "Poemas giratorios y otros poemas". Sin embargo, la estructuración propuesta por Huidobro no separa dos bloques temática o estilísticamente discernibles; por el contrario, encontramos a lo largo de la lectura poemas que aluden a otros anteriores, que desarrollan imágenes previamente propuestas o que reescriben con distinto modelo combinatorio alguna secuencia ya anticipada. Este carácter "giratorio" de algunas imágenes y motivos afecta a las dos partes del libro, pero también nos remite a otras obras anteriores.

Los estudiosos que se han ocupado de esta obra coinciden en subrayar su carácter heterogéneo y la difícil aprehensión de muchos de sus poemas. Saúl Yurkievich advierte una coexistencia ambigua de dos tendencias distintas:

Coexisten las dos tendencias básicas de Huidobro: expresionismo y formalismo, que se manifiestan aisladamente $o$ amalgamadas. Por un lado se da una poesía de confesión personal, apasionada, visceral, angustiosa, que tiende a la fusión entre la subjetividad y la palabra;y por el otro, una actitud lúdica y experimental, de distanciamiento frente al lenguaje, que lo impersonaliza, que reconoce la 
arbitrariedad del signo lingüístico y que busca lo verbal intrínseco, activar las energías de la lengua librada a su propio movimiento (95-96).

Estas dos tendencias, formalismo y subjetivismo, son interpretadas por Yúdice como dos vertientes complementarias a través de las cuales se busca la motivación poética: el formalismo y el juego gratuito de la palabra como mera producción semiótica, próxima a la poesía concreta ${ }^{3}$, busca la "autodefinición del texto"; mientras que la poesía de carácter subjetivista o expresionista persigue la "autodefinición del yo" (243). Todo ello está englobado, según este autor, en una búsqueda de la unidad del sujeto - escindido en Altazor-en un lenguaje absoluto. Esta búsqueda de armonía y el intento de resolución de los problemas críticos de la subjetividad ocuparán mayor espacio en El ciudadano del olvido, obra que en este sentido continúa y ahonda los aspectos existencialistas de Ver y palpar.

Sin embargo, Yúdice no cree posible establecer con exactitud la relación entre esas dos vertientes de Very palpar. El paso de un creacionismoimaginísticolingüŕstico, poéticamente estructurado en Poemas árticos, a este "creacionismo imaginístico-visual", "completamente inverosímil" (222), hace que este crítico apenas se arriesgue a señalar algunas isotopías formadas sobre la recurrencia de motivos como el ojo y la mirada. A lo largo de su análisis de Ver y palpar Yúdice insiste en las dificultades que ofrecen estos poemas, debido a que sus elementos ya no se estructuran en torno a un centro cohesor que les otorgue "verosimilitud estructural" y que "haga posible naturalizar las combinaciones anómalas" (220). A ello atribuye la abundancia de "imágenes impertinentes y a menudo absurdas" (215) que pueblan sus páginas.

Pero si desde un punto de vista lingüístico y desde las perspectiva de la gramática textual estos poemas no encuentran su "naturalización", desde una perspectiva más englobadora, atendiendo a otros textos de Huidobro y a sus propias referencias a la poesía desde el poema mismo, sí parece posible encontrar una interpretación no exhaustiva, pero sí más comprensiva de Ver y palpar.

${ }^{3}$ En la obra que venimos citando, Yúdice considera poemas concretos los titulados "Fuerzas naturales", "Naturaleza viva", "Ella", "Canción de Marcelo Cielomar" entre otros. En su trabajo, a la luz de la definición de poesía concreta dada por Max Bense, reduce a un sentido vinculado a la pura materialidad estructural y semítica del lenguaje la significación de estos poemas. Por otra parte, al vincular poemas como "Hasta luego", "Es un decir", "Esta cabeza paseando por el mundo", "Poemas giratorios", "El paladín de la esperanza" y "La suerte echada" con la escritura automática surrealista, y al afirmar que más allá de ciertos significados contextuales "se tienen que entender literalmente", está cerrando el acceso a ciertos niveles de esos textos que, vistos con una perspectiva más abarcadora, ofrecen algunas claves significativas para su comprensión. 


\section{CREACIONISMO, AUTOEXEGESIS Y METAPOESIA}

Aunque Navarrete Orta en su trabajo sólo concede rango de texto programático al conocido "Arte poética" que abre El espejo de agua, a lo largo de toda la poesía de Huidobro puede detectarse, semioculta en la simbolización poética y en la lógica de un discurso definido como "mágico", una prolongada y obsesiva referencia al poeta, a su canto y a la esencia de la poesía. Dicho con otras palabras, la reflexión poética de Huidobro no se agota en sus manifiestos; en su poesía, mediante la práctica de una poesía autorreferencial o autoexegética, en la que, a través de motivos metapoéticos se alude a los avatares de la creación y al poeta mismo, Huidobro demuestra también su autoconciencia y la obsesión por su meta artistica. Todo ellorevela una preocupación en la que se entrecruzan la doctrina teórica y la praxis poética en un esforzado ejercicio de autoanálisis.

Esta preocupación, que podemos vincular con el romanticismo y el modernismo, es para nosotros el resultado de una ficcionalización del poeta y de su oficio, que aparece así autodefinido en sus textos para mostrar las distintas facetas de la creación y la condición gozosa y doliente de quien lo posee. El yo poético que sustenta los poemas huidobrianos suele ser un poeta (a veces simbolizado mediante la figura del pájaro o del músico) que experimenta y plasma distintos estados poéticos: la emergencia de un canto que no acaba por brotar, el miedo a la pérdida del poder creador, el abandono de la plenitud poética o el fluir, en mero alarde creativo, de su dicurso inspirado, discurso paródico que otras veces cuestiona la tradición literaria heredada.

Estos elementos metapoéticos afloran con constancia desde El espejo de agua, $\mathrm{y}$ vienen a constituirse como el rasgo más relevante y permanente del creacionismo de Huidobro. Poemas como "Vates", de Horizon Carré o "Vermouth", "Llueve", "Adiós", y "Marino", de Poemas árticos, por citar sólo algunos, nos muestran respectivamente la posesión plena del poder poético (canto), la idea emersoniana del poeta como voz de su tiempo, la dolorosa emergencia del canto y la muerte del poder poético. El conjunto de las referencias metapoéticas de Poemas árticos nos muestra la tensión entre el poder poético y su pérdida, causada por fuerzas amenazantes que provienen de un mundo en conflicto y de una sensibilidad herida. Los dos últimos poemas del libro, "Vaso" y "Mares árticos" enuncian la pérdida del poder poético desde dos perspectivas complementarias: en "Vaso" se nos presenta una puerta abierta a la noche y un hablante poético que siente niebla en la mirada. La presencia de un "pájaro sonámbulo" y el anuncio de la muerte del ruiseñor nos hablan de la irrupción de elementos incontrolables (del subconsciente) y de la consiguiente esterilidad poética: "Y mi pecho desierto/ Ayer henchido de versos" (316). En "Mares árticos" ya no son fuerzas oscuras de ahogamiento y naufragio, sino el fuego, quien castra el don poético: "Entre las nubes se quema un pájaro" (316). Los últimos versos de este poema que cierra Poemas árticos implican la extinción de la poesía, pero también su renovada búsqueda: "Sobre los mares árticos/ Busco la alondra que voló de mi pecho" (317). 
Estos dos poemas parecen emblemáticos de lo que será la dialéctica poética de Huidobro en sus dos libros de 1925. Tanto en Automne Régulier como en Tout à coup asistimos no sólo a la irrupción de un nuevo sentimiento poético, vinculado a la percepción absurda, caótica y mecánica del mundo y de la existencia -expresada con un lenguaje poético igualmente nuevo-, sino también a una renovada persistencia en la búsqueda poética. Si el primer aspecto enfrenta a Huidobro con unas vivencias y una expresión de las mismas próximas al surrealismo, el segundo nos mostrará la fragilidad de un empeño poético que pretende prolongar los poderes del poeta-dios contra una realidad acosadora y tumultuosa, movida por leyes que escapan a su dominio.

En este mundo regido por el desorden -esto es, por un orden no poéticoel sujeto enunciante se define como "piloto sin navío y sin ley", en cuyo interior siempre cantará el "poeta ahogado” (“Automne régulier”, 319). En este poema el molino y su circularidad abre un nuevo ritmo temporal en el que todo "gira en vano". La definición del poeta, así como ese motivo giratorio, nos remite a la aventura de Altazor. El mundo de las creaciones puras y del poeta dueño de su inspiración se ha cerrado. Ahora, como leemos en "Relatividad de la primavera", "al fondo de mi armario el universo se deshace/ No hay nada que hacer contra la noche que nace" (325). Sin embargo, la voluntad creadora o la rebeldía del poeta enunciante se hace patente a lo largo de otros poemas de este libro, como ese personaje insomne que combate al caos y a la noche mientras se llena de escepticismo. Pese a las adversidades y a los altibajos del ánimo poético, hay textos en los que aflora de nuevo, ahora dolorosamente, la condición creadora del poeta. Así en "Afiche" se recupera la imagen de la garganta para situar el advenimiento poético, tratado como un síntoma fisiológico: "Ese pájaro en la garganta me hace mal". Finalmente una imagen ascensional indica la emergencia del poder poético o de la visión poética: "Estos hilos que al horizonte suben/Son las cuerdas olvidadas de mi violín" (335). En poemas como "La marinera" aparecen, asociados, dos elementos recurrentes en Ver $y$ palpar: el ojo, órgano de contacto con la realidad y de la videncia poética, y el mar, símbolo que en este libro puede apuntar a la temporalidad, a la extensión ilimitada del mundo real, a las sorpresas del azar, al naufragio (poético) y al espacio de la divagación de la mirada: "Mi ojo más que mi navío divaga/Por más que yo sea el marino preciso/ Qué queréis" (345). Parece como si los dictámenes de la "precisión", precepto del primer creacionismo, deban ser irremediablemente abandonados. La poesía de Huidobro, que desde este libro mezcla su voz con los ruidos del mundo y con el juego de las apariencias de la realidad, por las que divaga el ojo del poeta, persistirá, sin embargo, en el esfuerzo por "colonizar el dolor", dominar los recuerdos, los sentimientos, salvar el peligro de la ceguera artística y de los acosos irracionales. Ese es el contenido de "Poema", texto con valor de "arte poética" que cierra el libro. Ahí parece definirse la vocación de una poesía que trascienda la contingencia de la realidad, sus pequeñas parcelas acotadas, "las sábanas del ojo" que dificultan la percepción poética. Se propone 
ahora "un viaje sin sueño", "buscando las palabras que cuelgan del cielo" (349). Esta búsqueda de absoluto, aś como la implícita admonición a la purificación del ojo y la ubicación de lo poético en un espacio celeste nos remiten, como varios poemas más del libro, a Altazor, al manifiesto Total y a varios aspectos que cobran cuerpo en Ver y palpar: la crítica a la parcelación de la realidad por una estrecha perspectiva sobre la existencia y la crítica a una paralela insuficiencia de la poesía vigente en su momento para expresar los anhelos de unidad del hombre.

Este último poema de Automne Régulier es retomado al inicio de Tout à coup. El poema número 7 ironiza nuevamente sobre los tópicos literarios y sobre la mirada de escaso radio abarcador de los poetas: "Cantad la miel poetas cantad/ La miel que ha hecho célebres a las abejas" (355). Este poema introduce además un recurso paródico que cobrará mayor consistencia en Ver y palpar: la utilización de fórmulas de cortesía social y ciertas convenciones burguesas para ridiculizar un determinado tipo de actitud estética o existencial: "Produces un buen efecto", "Nuestra reina es una maravilla/ Tiene más prestigio que los sonetos" (355). El poema 29, donde se oponen "álbum de ecos" y "misal" a la fuerza desmedida del volcán, parece aludir también a los resortes miméticos y pautados por la tradición que rigen a la poesía no creacionista. El poema 30, extremando la crítica a la situación estética, parodia la saturación de la poesía por sus tópicos (libélulas) y por sus contenidos sentimentales o subjetivos (nervios palpitantes): "Señora hay demasiados pájaros/En vuestro piano/ Que atrae al otoño sobre una selva/ Espesa de nervios palpitantes y libélulas" (377). El cuestionamiento de tópicos artisticos y de contenidos sentimentales está presente también en Altazor -recordemos los versos "Basta señora harpa de las bellas imágenes" (406) y "Desconfía del ardid ceremonioso Y Y de la poesía" (398)_, pero el procedimiento paródico y el léxico utilizado concuerda, más que con este poema, con algunos de Ver y palpar.

Otros poemas, como el 25, también presentan grandes conexiones con Ver y palpar y El ciudadano del olvido en tanto que tratan poéticamente el tema de la poesía en relación con el peso de la existencia, los recuerdos, la madurez. En este poema el sujeto enunciante vislumbra un mañana poético en el que conocerá "el martillo de la edad" y también el peso "de las emociones que salen/ Que salen mañana" (371). En el poema 28 el hastío se suma a la edad y a los temores por el envejecimiento. En clara referencia a Altazor se piensa en abandonar la aventura de la creación: "Dejemos los paracaídas a medio camino/ Las historias se dispersan todas las noches/ Cuando brota la rosa del hasta luego" (375). Ese "hasta luego" aparecerá como giro igualmente sustantivado en varios poemas de Very palpar, y parece aludir, -al menos así se nos presenta en el contexto conceptual de este poema - a la inestabilidad de lo poético, representado por esas historias que se dispersan: historias que bien pueden ser proyectos poéticos que ante la irrupción de elementos caóticos o del mismo desfallecimiento creador no llegan a tomar cuerpo. 


\section{4. “TENEIS LENGUA DE PRINCIPES ...” ENTRE LO CURSI Y LO ABSOLUTO}

Los mismos altibajos en la percepción y plasmación poética presentes en Automne Régulier y Tout à coup, las mismas ansias de poesía plena y los mismos acosos que dificultan su instauración; la misma sensación de caos y deterioro ante la presencia siempre acechante de la muerte están presentes en Ver y palpar. Pero también la rebeldía poética y los alardes de poesía "creada". El primer poema del libro, "Hasta luego", alude, como varios de los anteriores, a Altazor: "Os traigo los recuerdos de Altazor/ Que jugaba con las golondrinas y los cementerios / Los molinos las tardes y las tumbas como bolsillos del mar" (461). Sin embargo, la evocación del héroe caído desde la altura de su ambición poética, no es, como ha sugerido Yúdice, una citación arbitraria, mal cohesionada con los distintos poemas que la actualizan. En este caso concreto, en la estrofa precedente, el poeta enunciante ha preguntado "Qué altura me dáis para el veraneo del cráneo/ Os desafío a todos os desafío". Evocar la altura de Altazor, "que se fue de su carne al viento estupefacto", es una forma de desafío a un mundo envuel to en el "apacible perfume", "bajo la calma mirada del viento". La segunda parte del poema incidirá nuevamente en un mundo de convenciones estéticas: "piano de palabras amadas por los siglos", "oro" y "piedras de milagro/ Robadas en el cofre de los poetas enamorados". Un imperativo ordena cerrar los sentidos tanto a estos tópicos como al dolor y a "las proyecciones del calor interno", es decir a los sentimientos. También la tercera parte de "Hasta luego" ridiculiza el carácter repetitivo de los hábitos poéticos tradicionales cuando invita a un "tú", "Vendedor de luces conocidas como el sonido de los tambores" a aproximarse a la verdadera magia poética de las "miradas recién nacidas" (462). El poema IV de la misma serie llama nuevamente a una aventura que en el $\mathrm{V}$ se describe como peligrosa y amenazada por el naufragio y por el Juicio Final, aunque en el poema VI se asciende al umbral del vértigo poético: los labios, órganos del canto, están "Hinchados por el calor y por la altura" (463). En el poema VI aparece un nuevo cuestionamiento de la tradición poética mediante un canto irónico al Rin y a su "agua cinematográfica". Una estrofa metapoética nos remite nuevamente al acento crítico de las obras anteriores: "El ruiseñor está amarrado por sus cantos/ $\mathrm{Al}$ árbol de su gusto exquisito/Mientras dice sus amarguras de noche" (464).

Como ya vimos en los poemas 29 y 30 de Tout à coup, estas secuencias cuestionan la tradición poética heredada y conectan con un eje vertebral de Altazor: su proyecto de dinamitar la lengua poética para hacer triunfar un nuevo proyecto de absolutismo estético. Sin embargo, un texto programático de 1932 ya citado, el manifiesto "Total" parece unificar todas estas variantes poéticas en las que se parodia la poesía de "gusto exquisito". Allí leemos:

Basta de vuestros fragmentos y de vuestras pequeñas voces sutiles que hablan por una parte de vuestro corazón y por un dedo precioso. (...) El mundo os vuelve 
las espaldas, poetas, porque vuestra lengua es demasiado diminuta, demasiado pegada a vuestro yo mezquino y más refinada que vuestros confites. Habéis perdido el sentido de la unidad, habéis olvidado el verbo creador. (...) Tenéis lengua de principes y es preciso tener lengua de hombre (...) No se trata de negar tu oficio, pero tu oficio es oficio de hombre y no de flor (755-756).

Las coincidencias entre "Total" y los poemas de Ver y palpar no se agotan en la crítica a la debilidad poética que apreciaba Huidobro en su tiempo. Por otra parte, lo defendido en este manifiesto no sólo atañe al sentido "totalizante" de Altazor y de las obras publicadas posteriormente, sino que sintoniza con la misma conciencia crítica sobre la poesía presente ya en las dos obras de $1925 \mathrm{y}$, sobre todo, en Ver y Palpar. Otra secuencia del mismo manifiesto contribuirá a explicar un poema aparentemente confuso y arbitrario como "Los señores de la familia"4. El poema se inicia con la siguiente estrofa, que se repite con variantes léxicas vinculadas a los cinco sentidos:

Los ojos contra los ojos

El espacio contra el espacio

Señor qué hora es

No puedo contestarle

Soy el sobrino de la luna.

La estrofa final recopila las variantes:

Las voces contra las voces

La tierra contra la tierra

Los pies contra los pies

El cielo contra el cielo

La familia de los mudos tiene sangre de violín

Sale con el pie derecho a las calles de nuestros paisajes

Corta la naturaleza con un puñal

Y se aleja sobre un ojo que se pierde en el espacio (483).

Pues bien, un procedimiento similar es utilizado por Huidobro en "Total" para ilustrar la estrechez de los horizontes humanos frente a la amplitud humana que él propugna:

Basta de vuestras guerras adentro de vuestra piel o algunos pasos más allá de vuestra piel.

El pecho contra la cabeza, la cabeza contra el pecho.

4 Véase la interpretación que ofrece de este poema Mireya Camurati en Poesta y poética de Vicente Huidobro. Para esta autora "Los señores de la familia" incorpora el sentido lúdico y humorístico como medio liberador que se abre a "lo insolito, lo nuevo, lo maravilloso" (181). 
El ojo contra la oreja, la oreja contra el ojo.

El brazo derecho contra el brazo izquierdo, el brazo izquierdo contra el brazo derecho.

El sentimiento contra la razón, la razón contra el sentimiento, etc. (755).

En ambos textos se nos plantea una actitud reprobable para el verdadero poeta. Aunque el manifiesto es más explícito que el poema, en ambos podemos apreciar la expresión de un repliegue mezquino en los estrechos límites y compartimentos que el hombre se ha impuesto. Sin embargo, en la última estrofa de "Los señores de la familia" el contenido se amplía mediante una alusión al realismo, figurada por ese salir a "los paisajes” a cortar la naturaleza con un puñal. Aún así esos "señores de la familia" (¿artística?) son mudos con "sangre de violín".

También encontramos una esclarecedora correspondencia entre otros párrafos del manifiesto "Total" y el poema "Entre ambos" de Ver y palpar. Este poema, como la "Canción de la muervida" y "Pesos y medidas", entre otros, presentan una novedosa poetización de elementos pertenecientes a lo pautado, a lo medido y a lo regularizado por criterios convencionales. Así encontramos "los cálculos de la tempestad", "línea recta", "horario", "los números", "las medidas". Estos elementos aparecen preteridos respecto a un sentido de apertura, de liberación, planteada como misión urgente. La concordancia del mundo pautado del poema con el que Huidobro denuncia en el manifiesto es clara:

¡Ah, ya sé! La medida, la famosa medida. Sois todos muy medidos. Si a veces esto no fuera un pretexto, si a veces ello no sirviera sino para esconder vuestro vacío. Habéis nacido en la época en que se inventó el metro. Todos medís un metro sesenta y ocho, y tenéis miedo, miedo de romperos la cabeza contra el techo (756).

Esta alusión irónica a las medidas que recortan la amplia dimensión de las potencialidades humanas ilumina el sentido de la "Canción de la muervida". Aquí aparecen relojes, "un anillo en cada uno de los cinco sentidos" y el acto, visto como mezquino, de contar:

Llevan su cuerpo como el tallo de un nenúfar precioso

Y no van más lejos que un tiro de pistola

Cuentan los días con huesos de frutas

Que guardan en jaulas como pájaros

Cuentan las estrellas y les dan nombres amistosos y tibios

Es preciso no confundir los lechos y no equivocarse de plato

Es preciso cantar como un nenufar precioso (487). 
De nuevo, comoen Tout à coup, vuelven a confluir los hábitos burgueses con una estrecha concepción, cursi y exquisita, de la poesía. Ambas manifestaciones aparecen también unidas en el manifiesto "Total", y deben ser puestas en relación con la lucha opresiva contra un mundo de sentimientos y elementos sentimentales que Huidobro se esforzó por eliminar de sus poemas.

En contrapartida, se llama a la verdadera poesía totalizante, al poeta de "ancho espíritu sintético, un hombre total" (756). Esa totalidad exige el pleno desarrollo del hombre en su dimensión social, convicción que aparece en poemas como "Ronda de la vida riendo", donde en clave lúdica se plantea una utopía social unida a una armonía entre mundo-poesia-sociedad. Estas y otras referencias a ideales sociales, no exentas de conflictividad, deben ponerse en relación con la preocupación social y la actividad revolucionaria de Huidobro por esas fechas. En "El ángel Chaplin", por ejemplo, leemos:

Como todo hombre de inteligencia superior y de alto espiritu, tenías que venir tarde o temprano al campo de la lucha de clases y aportar tus fuerzas a los problemas sociales. Así lo declaran las pequeñas notas periodísticas de los afortunados que han logrado ver tu filme Nuevos tiempos. Y así tenía que ser. Piensa, amigo Chaplin, qué inmensas regiones se abren para tu arte, qué anchos horizontes para una renovación constante de tus medios de expresión (903).

Otros poemas de Ver y palpar obedecen también a los razonamientos expuestos en “Total” y se expresan mediante fórmulas paródicas próximas a las ya descritas. En este sentido podrían agruparse bajo el mismo tratamiento paródico poemas como "Ella", "El célebre océano", "Noche y día" y "Naturaleza viva". Los tres contienen diversas fórmulas de cortesía y actitudes de comedido comportamientoque, pese a dificultades interpretativas particulares, los vinculan con ese mundo de muertos vivientes parodiado en claves emanadas de "Total".

Algunos poemas del libro tienen categoría de "arte poética" en su totalidad: "Halo", que llama a la liberación contra las fuerzas opuestas de retención y oscuridad; "El paladín sin esperanza", donde el poeta agredido "en la zona del canto" llama nuevamente a la aventura altazoriana y a la introspección, para oír "los rumores de tu pecho sepulcro del héroe" (474); "Ruiseñor anónimo", donde aparece la incomprensión del mundo hacia el canto y su alejamiento para morir, en contraste con "Contacto externo", donde se aboga por la proyección o la extraversión del poeta hacia el mundo. "La estatura de la sombra" tiene un tono de ascenso glorioso a la plenitud poética, dejando atrás las sombras. Ese sentido positivo lo conecta con algunos escasos poemas en los que se mantiene ese tono de triunfalismo poético: así con "Fuerzas naturales" y "Poema para hacer crecer los árboles", donde parece reinstaurarse el orden poético frente al caos, o con "Canción de Marcelo Cielomar", alarde lúdico sobre una base léxica sometida a permutaciones diversas. 
Sin embargo, en el contexto global de Ver y palpar, no son frecuentes estos poemas de signo totalmente positivo. Generalmente la angustia, el caos existencial, la avalancha de elementos subconscientes (representados en "Sin por qué" por la ocurrencia del vocablo "arum") tienden a hacer del mito creacionista, visto como lucidez libertadora, un desideratum que no llega a cumplirse. Si en un poema como "Preceptiva funesta" se anuncia el nuevo poema por nacer - recordando, por cierto, las ideas sobre el adjetivo plasmadas en el "Arte poética" de 1916-y se proclama "Mueran las solicitaciones al sentimiento/Y muera la emoción gritada por las noches" (499), también es cierto que el mismo texto remite a las intermitencias del poder creador y al grado de sufrimiento que la misión poética entraña: "Palabra mi palabra tu palabra/Los tumultos que te rompen la garganta/ Las palabras se cargan y descargan día y noche" (498). Idea similar al poema 28 de Tout à coup donde se experimenta el desaliento creador.

Aunque no hemos realizado un seguimiento exhaustivo de la reflexión metapoética y metacreacionista de Ver y palpar, sí parece posible que con esta obra, y más ampliamente, desde Automne Régulier y Tout à coup, la idea del poeta-dios se resquebraja progresivamente y no puede ser sostenida en la praxis poética huidobriana. Del mismo modo, la aversión teórica de Huidobro al surrealismo -que deberia ser matizada a la luz de las mismas referencias metapoéticas que lo aluden - contrasta con unos textos y una actitud poética que, aún dejando constancia de cierta resistencia a la penetración de materiales oníricos surrealistas, no puede menos que considerarse "surrealizante".

Por otra parte podemos extraer del trabajo realizado, a la vista de la homogeneidad entre varios aspectos metapoéticos de Automne Régulier, Tout à coup y Ver y palpar, la certeza de que la periodización de la obra huidobriana debe ser revisada y reordenada no tanto por las fechas de su publicación, sino por las aglutinaciones de sentido que ella presenta en determinados períodos. Así, el período 1925-1941, de cuyo estudio hemos ofrecido una anticipación, muestra una homogeneidad que induce a reconsiderar el tradicional corte metodológico establecido en la fecha de 1931.

Como puede verse, cuando Huidobro publica los dos libros de 1925 en francés y rompe con el estilo creacionista-cubista anterior no abandona ese afán metapoético. Si la exploración semántica y la búsqueda de coherencia interna del poema se relajan, no se abandona la obsesión por la poesía misma. Prueba de ello es la cantidad de imágenes metacreacionistas que pueblan aún la poesía de Huidobro, y que tienen su origen en sus primeras obras. Con distintas variantes, esta línea atraviesa toda la obra de Huidobro y cobra un máximo protagonismo en Altazor ${ }^{5}$. Como hemos visto someramente, de estas imágenes

\footnotetext{
${ }^{5}$ En el libro Altazor, la teorta liberada (Santa Cruz de Tenerife: Ed. Pilar Rey, 1987) hemos propuesto una lectura metacreacionista del poema, tomando como base las secuencias autorreferenciales referidas al poema y al creacionismo dispersas en algunos de sus cantos.
} 
depende en gran medida la unidad significativa de poemas tan dispares en su factura y tan arbitrarios en su codificación como los de Ver y palpar.

Todo ello nos lleva a concluir que el creacionismo de Huidobro no radica tanto en las distintas formas en que modula, estructura y construye sus poemas (cubista, surrealista, etc.), ni en un determinado mecanismo de la imagen, sino más bien en una constante, aunque variable, insistencia en la reflexión sobre la creación poética. En relación con este aspecto nos gustaría terminar recordando unas palabras de Enrique Caracciolo Trejo, donde afirma que "Huidobro no parece urgido por interrogantes existenciales. Su ser, su yo, no son jamás cuestionados. Su poesía es fruto de una vitalidad que surge incontenible de su mente"(83). Sin embargo, una lectura de todas las secuencias autorreferenciales y metacreacionistas de la poesía de Huidobro nos deja el saldo de una experiencia agónica, sustentada en la fragilidad y en la esencia siempre esquiva de la creación.

\section{BIBLIOGRAFIA CITADA}

Huidobro, Vicente, Obras completas (Tomo I). Santiago de Chile: Ed. Andrés Bello, 1976.

Bary, David, Huidobro o la vocación poética. Granada: Universidad de Granada, 1963.

Costa, René de, "Introducción" a Vicente Huidobro, Altazor. Temblor de cielo. Madrid: Cátedra, 1981.

Camurati, Mireya, Poesía y poética de Vicente Huidobro. Buenos Aires: Ed. Fernando García Cambeiro, 1980.

Caracciolo Trejo, Enrique, La poesia de Vicente Huidobro y la vanguardia. Madrid: Gredos, 1974.

Navarrete Orta, Luis, Poesía y poética en Vicente Huidobro(1912-1931) Caracas: Universidad Central de Venezuela, 1988.

Yúdice, George,Vicente Huidobro o la motivación del lenguaje. Buenos Aires: Galerna, 1978.

Yurkievich, Saúl, "Vicente Huidobro: el alto azor", en Fundadores de la nueva poesía latinoamericana. Barcelona: Ed. Barral, 1973. 